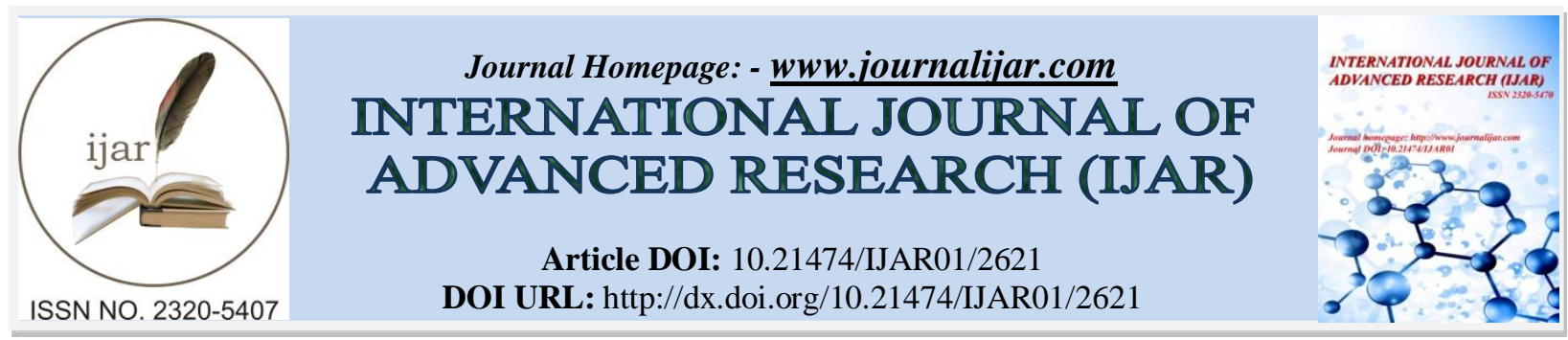

RESEARCH ARTICLE

\title{
FOURNIER'S GANGRENE : APPROACHES TO DIAGNOSIS AND TREATMENT OF BANGLADESHI PATIENTS.
}

\author{
Dr. Avisak Bhattacharjee, Dr. Md. Ashrafuzzaman and Dr. Md. Mahbubur Rahman. \\ 1. MBBS FCPS (Surgery) MPH (Hosp. Admin.) FMAS (Lap. Surgery) PhD research fellow (BUP). \\ 2. MBBS MS (Surgery). \\ 3. MBBS FCPS (Surgery).
}

\section{Manuscript Info}

Manuscript History

Received: 30 October 2016

Final Accepted: 29 November 2016

Published: December 2016

Key words:-

Fournier's Gangrene.

\section{Abstract}

Fournier's gangrene is a rare, rapidly progressive, necrotizing fasciitis of the external genitalia and perineum. The main aim of this study was to observe comprehensively the disease profile of Fournier's gangrene, with a specific intent to observe the proportion of patient present with Fournier's gangrene.

Methods: Initially all the patients were enrolled by purposive sampling from the admitted patients of department of surgery of Chittagong Medical College Hospital and Sir Salimullah Medical College and Mitford Hospital. Thereafter they were finalized according to the eligibility criteria. 22 patients were finalized. Patients were thoroughly evaluated and managed and during management data regarding demographic, clinical and biochemical as well as treatment profiles were recorded. Data were managed, edited and plotted in tabular and figure form. Mean $\pm \mathrm{SD}$ was determined. Data analysis was done by chi square test. p value was significant at $<0.05$.

Results: The mean age of the patients was $43.9 \pm 14.82$ years. $68.2 \%$ patients showed insiduous onset whereas $31.8 \%$ showed abrupt onset. Both cutaneous and anorectal factors claimed the highest $36.4 \%$ of etiology. Pain (100\%) and edema (100\%) were the prime manifestations. In $59 \%$ cases testes were not exposed but in rest $41 \%$ cases testes were exposed. In case of $36.4 \%$ cases only scrotum was involved whereas in case of $22.7 \%$ cases both scrotum and perineum were involved. After provision of aggressive treatment in $72.7 \%$ cases no complication was observed. 9.1\% of total patients expired during treatment and rest patients ultimately survived.

Conclusion: Elderly and low economic profile people are frequently affected. To reduce the significant morbidity and mortality aggressive medical and surgical management is mandatory.

Copy Right, IJAR, 2016,. All rights reserved.

\section{Introduction:-}

Fournier's gangrene is a variety of necrotizing fasciitis of the genital, perianal and perineal regions which may extend up to abdominal wall between the fascial planes; it is a rare disease which expresses as rapidly progressive and fulminant from ${ }^{[1]}$. A French dermatologist and venerologist named Professor Jean Alfred Fournier (1832-1914) 
described first this clinically devastating condition in $1883^{[2]}$. He basically described a syndrome of unexplained gangrene in the penis and scrotum in 5 young men with no other pathology basis of sudden onset and rapid progression $^{[3]}$.

The basic pathology of mother entity of Fournier's gangrene, necrotizing fasciitis is the damage of subcutaneous fat layer (containing nerve and vascular structures ) as well as the superficial and deep fascia layers. Hippocrates first mentioned necrotizing fasciitis in $500 \mathrm{BC}$ as a complication of 'erysipelas'; an acute and often recurring bacterial infection ${ }^{[4]}$. The disease is characterized by on obliterative endarteritis of small blood vessels of the subcutaneous tissue secondary to polymicrobial infections acting synergistically to allow rapid invasion and tissue necrosis ${ }^{[1]}$.

The precise etiologies of the disease remain unclear. Initially Fournier's gangrene was defined as on idiopathic entity, but now-a-days, it is accepted as the disease of either perineal or genital skin infections. Anorectal or urogenital and perineal trauma, including pelvic and perineal injury or pelvic interventions are other causes of Fournier s gangrene ${ }^{[5]}$. Diabetes mellitus and chronic alcoholism are responsible for $20-70 \%$ and $25-50 \%$ patients respectively ${ }^{[6]}$.

The clinical features and relevant investigations are the mainstay of diagnosis. This gangrene apparently shows vast heterogeneity in clinical presentation from insidious onset and slow progression to rapid onset and fulminant course , the latter being the more common presentation ${ }^{[7]}$. The infection commonly starts as cellulites adjacent to the portal of entry, depending on the source of infection, commonly in the perineum or perianal region . Locally significant pain and swelling with crepitus are common features ${ }^{[8]}$.

Necrotic patches starts to appear on overlying skin and progress to extensive necrosis if subcutaneous inflammation worsens. Sepsis and multi organ failure are the common causes of death if not aggressively treated . So, systemic manifestation is also a deteriorating sign of Fournier's gangrene. A scoring system (Fournier's gangrene severity index) was developed by Laor et al. to quantify the severity of infection, using common vital signs and laboratory data ${ }^{[7]}$. This score helps to predict the mortality. The patients having score $>9$ have $75 \%$ mortality chance while the patients having score $<9$ have $78 \%$ probability of survival. The limitation of this scoring that it can't predict the length of hospital stay which was first marked by Chawla et al ${ }^{[9]}$.

Fournier's gangrene has a long list of differential diagnoses. Investigations are aimed to identify the cause \& concomitant diseases to enable effective treatment. The treatment consists of urgent resuscitation, use of broad spectrum parenteral antibiotics, aggressive surgical debridement, tetanus prophylaxis and supportive care followed by subsequent reconstruction of the residual defect ${ }^{[10]}$. Despite modern intensive care unit (ICU) management the mortality rate of Fournier's gangrene is still remain high $(3-67 \%)^{[11]}$.

In Bangladesh, we encounter a good number of patients in our hospitals. So, we don't want to agree with recognized western medical books that Fournier's gangrene is a rare disease. There is no previous study on this relatively common serious clinical entity in our country. So, it will be appropriate to make an effort on this ground in our perspective. This present study aimed to observe comprehensively the disease profile of Fournier's gangrene, with a specific intent to observe what proportion of patient present with Fournier's gangrene.

\section{Materials and Methods:-}

This study was conducted in the department of Surgery of Chittagong Medical College Hospital and Sir Salimullah Medical College and Mitford Hospital from June 2008 to May 2009; total 12 months duration. This was a cross sectional prospective observational study where the subjects were selected by purposive sampling. Eligibility criteria includes clinical features consistent with rapidly progressive fulminating infection arising primarily from the perianal, perineal and genital region and presence of necrotic tissue on surgical exploration.

The initial clinical evaluations were done by taking adequate history, proper physical examinations and some relevant investigations. A blood sample was collected to do the complete blood count, random plasma sugar, serum creatinine, serum albumin, LDH, liver function test, electrolytes and culture-sensitivity. Thereafter, a wound swab was collected and sent for culture. A urine sample was collected \& sent for routine and microscopic examination and culture. 
Initial resuscitation was done with crystalloids or crystalloids and whole blood; as per required. Broad spectrum parenteral antibiotic was started on empirical basis. After resuscitation aggressive debridement of all dead tissues, followed by irrigation of wound with hydrogen peroxide and normal saline. The wound was covered with EUSOL soaked gauge. Tissue was taken and sent for histopathological examination.

Urethral catheterization was done aseptically where needed. The wound was checked regularly. Regular dressing was done. In some cases repeated surgical debridement was needed. When healthy granulation tissue appeared and the size of the wound reduced, resurfacing of the wound was done by the secondary suture technique and in some cases, partial thickness skin graft \& Local pedical flap graft was done. The exposed Testis was implanted in to the medial aspect of Thigh. From the admission physiological and laboratory parameters FGSI was calculated.

Before approaching for the study proper ethical clearance was taken from the Ethical Review Committee (ERC).

\section{Statistical analysis:-}

Data were collected by a pre-structured, peer reviewed case record form (CRF). Collected data were compiled and statistically analyzed by using computer based programmed statistical package for social science (SPSS) for windows version- 12. Chi-square $\left(\mathrm{x}^{2}\right)$ test, Student's ' $\mathrm{t}$ ' test, were done to make inference. P-value <0.05 was considered as significant.

\section{Results:-}

Table I:- Description of Variables found in the study population.(n=22)

\begin{tabular}{|c|c|c|c|}
\hline Patients Variables & Minimum & Maximum & Mean ( $\mathbf{S t d}$ Deviation) \\
\hline Age (in years) & 18 & 75 & $43.9( \pm 14.82)$ \\
\hline Weight (in Kg) & 48 & 70 & $58.59( \pm 5.35)$ \\
\hline Fever (in $\mathbf{0}^{\mathbf{F}}$ ) & 99 & 103 & $101.2( \pm 1.14)$ \\
\hline Number of Debridement & 1 & 4 & $1.64( \pm 0.9)$ \\
\hline Hospital Stay (in days) & 5 & 77 & $31.86( \pm 23.48)$ \\
\hline FGSI & 1 & 14 & $5.530( \pm 3.4)$ \\
\hline Delay (in days) & 2 & 15 & $7.68( \pm 3.98)$ \\
\hline
\end{tabular}

A total of 22 cases of Fournier's gangrene treated in the department of surgery of study places between June 2008 to May 2009 were studied. All the patients were male. The mean $( \pm$ SD) age of the patients was 40.90( \pm 14.82$)$. The mean $( \pm$ SD) body weight was $58.95( \pm 5.34) \mathrm{kg}$. The mean $( \pm \mathrm{SD})$ body temperature of the patients at hospital admission was $101.22( \pm 1.14){ }^{0} \mathrm{~F}$. The mean $( \pm \mathrm{SD})$ delay between onset of the disease and hospital admission was $7.68( \pm 3.98)$ days. The mean $( \pm \mathrm{SD})$ hospital stay was $31.86( \pm 0.90)$ times. Time mean Fournier's gangrene severity index (FGSI) was 5.5( \pm 3.44$)$ (Table-I).

Out of total 22 patients $9(40.9 \%)$ were day laborer, $5(22.7 \%)$ were farmer, $4(18.1 \%)$ were service holder and rest $4(18.1 \%)$ belong to others where businessman, drivers and teachers were included (Figure-I).

At the time of hospital admission, 9(68.2\%) patients presented with an abrupt onset and 7(31.8\%) cases presented with an insidious onset (Figure-II).

Though diabetes is a common predisposing factor in development of Fournier's gangrene, only $4(18.2 \%)$ cases in our study were diabetic . 10(45.5\%) patients were from poor social class, 2(9.1\%) patients were alcoholic and 1 $(4.5 \%)$ patient was associated with carcinoma rectum. $5(22.7 \%)$ patients in our study had no associated risk factor (Figure-III). 


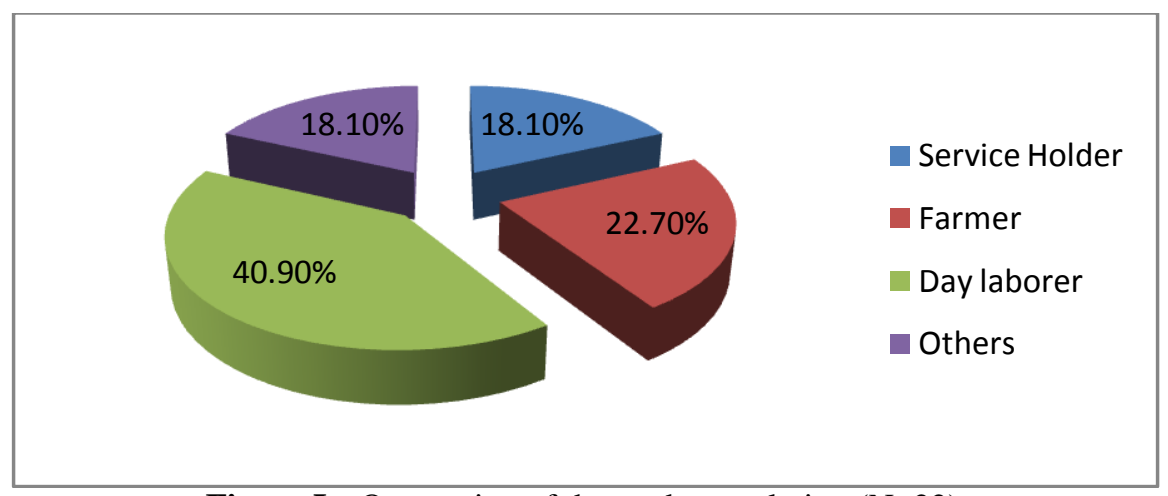

Figure I:- Occupation of the study population $(\mathrm{N}=22)$.

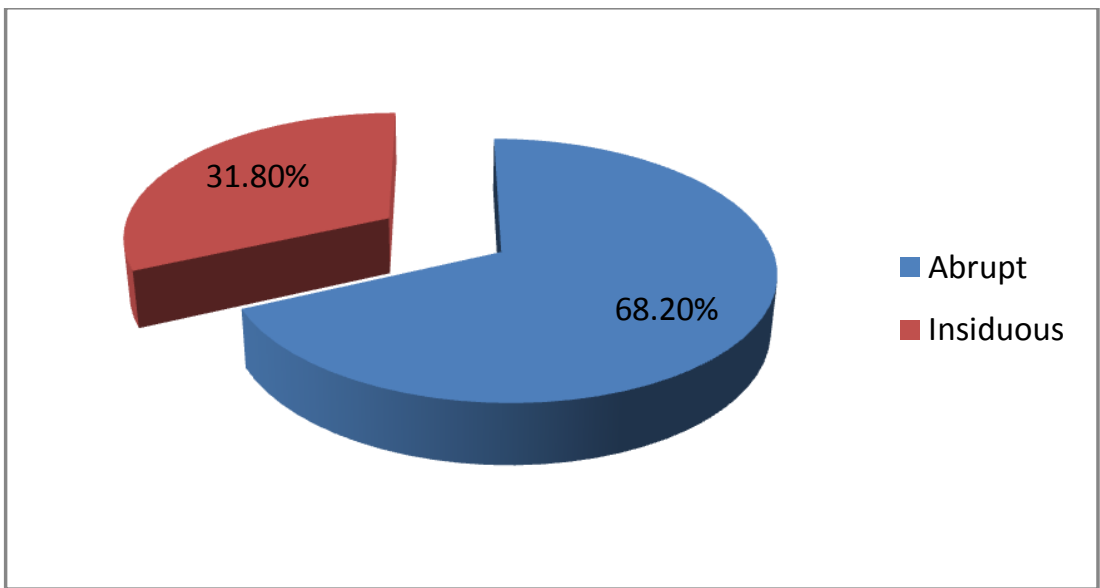

Figure II:- Onset of the disease ( $\mathrm{N}=22)$

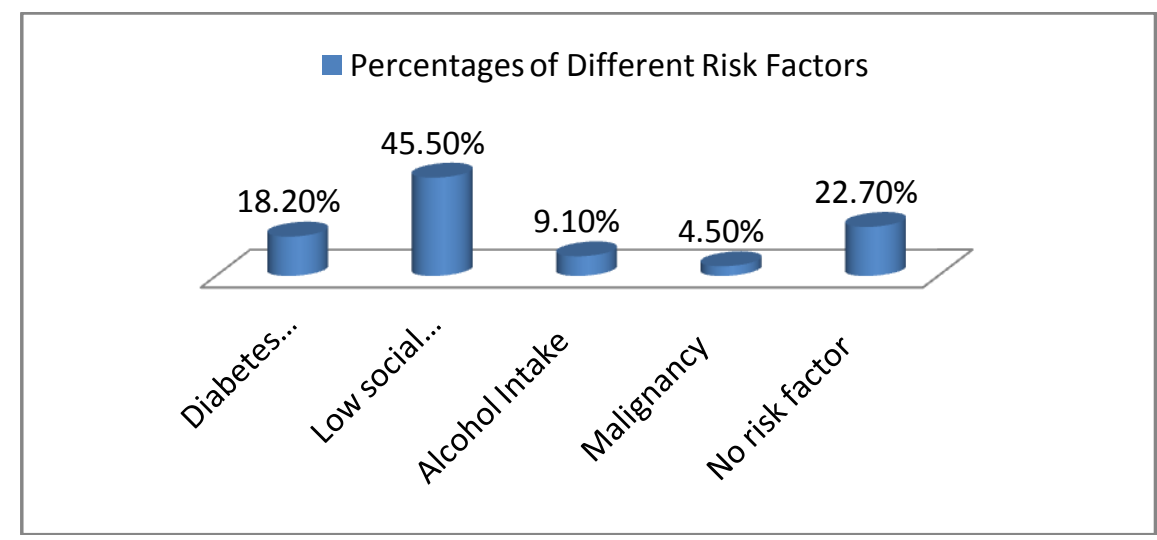

Figure III:- Distribution of the study subjects according to associated risk factors (N=22).

Table II:- Distribution of the study subjects according to etiology (N=22)

\begin{tabular}{|c|c|c|}
\hline Etiology & Frequency & Percentage \\
\hline Cutaneous & 8 & 36.4 \\
\hline Anorectal & 8 & 36.4 \\
\hline Post operative & 1 & 4.5 \\
\hline Unknown & 3 & 13.6 \\
\hline Urogenital & 2 & 9.1 \\
\hline Total & 22 & 100 \\
\hline
\end{tabular}


Out of 22 cases, the underlined etiological process could be identified in $19(86.4 \%)$ cases. The commonest cause was cutaneous (local skin sepsis) in $8(36.4 \%$ ) and colorectal (perianal abscess, hemorrhoids, fistula). In 8(36.4\%) cases urinary tract lesions (periurethral abscess, urethral stricture ) in $2(9.1 \%)$ cases, post operative $1(4.5 \%)$ cases. No cause was found in $3(13.6 \%)$ cases (Table II).

Table III:- Clinical presentation of Fournier's Gangrene( $\mathrm{N}=22)$

\begin{tabular}{|l|c|c|}
\hline \multicolumn{1}{|c|}{ Signs and Symptoms } & Frequency & Percent of patients \\
\hline Pain & 22 & 100 \\
\hline Edema & 22 & 86.36 \\
\hline Fever & 19 & 100 \\
\hline Erythema & 22 & 40.90 \\
\hline Crepitus & 9 & 100 \\
\hline Scrotal Skin necrosis & 22 & 18.2 \\
\hline Glycosuria & 4 & 72.2 \\
\hline Leukocytosis & 16 & 38.3 \\
\hline Shock & 8 & 45.5 \\
\hline Dysuria & 10 & \\
\hline
\end{tabular}

Among the presenting clinical features pain, edema, erythema, and scrotal skin necrosis were found in almost all the cases. Fever in $86.36 \%$ cases, Creptus in $40.90 \%$ cases, Glycosuria in $18.2 \%$ cases, Dysuria in $45.5 \%$ cases, Leukocytosis in $72.2 \%$ cases and Shock in $38.3 \%$ cases were evident (Table III)

On hospital admission, the testes were exposed after sloughing out of gangrenous tissue in 9(40.9) and 13(59\%) Testes were not exposed (Fig. IV).

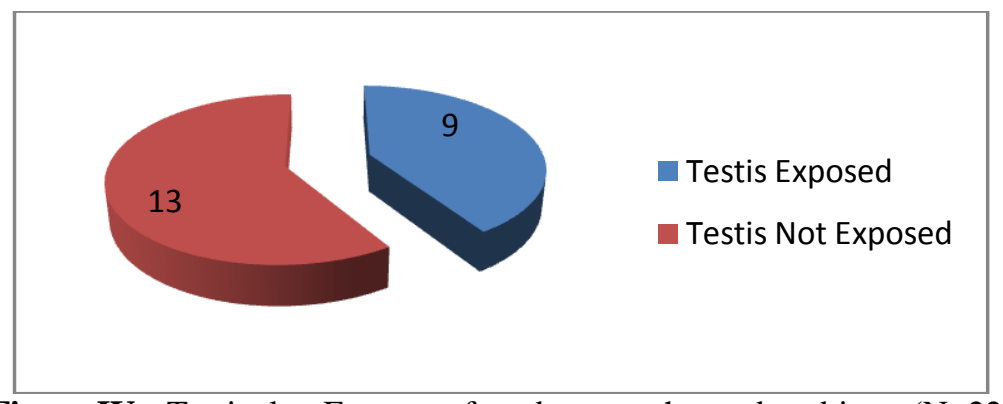

Figure IV:- Testicular Exposure found among the study subjects $(\mathrm{N}=22)$

Table IV:- Area involved in the necrotic process among the study Subjects $(\mathrm{N}=22)$.

\begin{tabular}{|c|c|c|}
\hline Area involved & Frequency & Percentage (\%) \\
\hline Scrotum & 8 & 36.4 \\
\hline Scrotum +Groin & 2 & 9.1 \\
\hline Scrotum + Anterior Abdominal wall & 3 & 22.7 \\
\hline Scrotum+ Perineum & 5 & 4.5 \\
\hline Scrotum+ penis & 1 & 4.5 \\
\hline Scrotum+ Buttock & 1 & 4.5 \\
\hline Scrotum + thing & 1 & 4.5 \\
\hline Scrotum & 1 & 100 \\
\hline
\end{tabular}




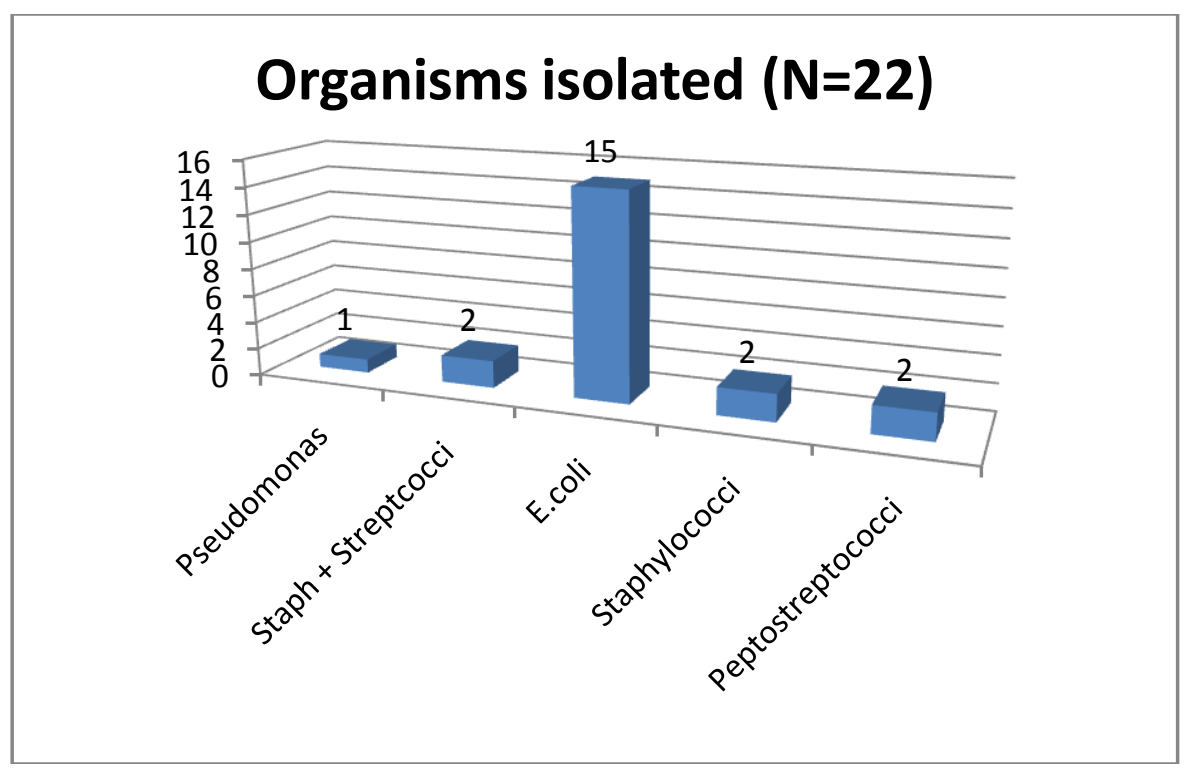

Figure V:- Organisms isolated from the wound $(\mathrm{N}=22)$

Area involved in the necrotic process had varied extension in to the surrounding tissues. Only Scrotum was involved in $8(36.4 \%)$ cases. Scrotum plus perineum in $5(22.7 \%)$ cases, Scrotum plus Groin in $2(9.1 \%)$ cases, Scrotum plus Anterior abdominal wall in $3(13.6 \%)$ cases and $1(4.5 \%)$ in each cases of Scrotum plus penis, Scrotum plus thigh , Scrotum plus Buttock, and Scrotum, Anterior abdominal wall plus thigh respectively (Table IV)

Pus was taken from wound for culture and sensitivity and yielded growth of many types of organisms in varying combinations. The organisms were indigenous commensals below the pelvic diaphragm and genital tract. They include Pseudomonas, Streptococci, Staphylococci, Peptostreptcocci . The most common organism isolated was E.coli 15(68.2\%) (Figure V)

Out of 22 patients $2(9.1 \%)$ expired. One patient died of Septicemia despite adequate resuscitation, wound debridement, the patient had concomitant renal failure, COPD, Carcinoma of rectum. Another patient developed ARDS followed by Multiple Organ Failure (MOF) (Figure VI).

During treatment $3(13.6 \%)$ patients developed ARDS and 1 (4.5\%) patient developed Septicemia, RTI and CRF with cardiac arrest each (Table VI).

Table IV:- Complications developed during treatment of study Subjects $(\mathrm{N}=22)$

\begin{tabular}{|c|c|c|}
\hline Complication & Frequency & Percentage \\
\hline No Complication & 16 & 72.7 \\
\hline Developed ARDS & 3 & 13.6 \\
\hline Septicemia & 1 & 4.5 \\
\hline CRF+ Cardiac Arrest & 1 & 4.5 \\
\hline Respiratory Tract Infection & 1 & 4.5 \\
\hline Total & 22 & 100 \\
\hline
\end{tabular}




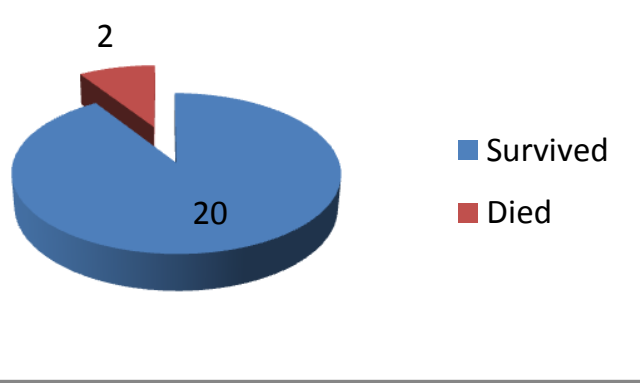

Figure VI:- Outcome of treatment among the study subjects $(\mathrm{N}=22)$

The table VII shows the comparison of survived and died patients according to delay of hospital admission.

Mean $( \pm$ SD) delay of survived patients was $7.50( \pm 4.05)$

Mean $( \pm$ SD) delay of died patients was $9.50( \pm 3.53)$

Statistical analysis with $\mathrm{t}$ - test showed significant difference $(\mathrm{t}=0.733, \mathrm{p}=<0.001)$ (Table VII).

The table VIII shows the comparison of Survived and died patients to FGSI.

Mean $( \pm$ SD) FGSI of survived patients was $6.95( \pm 3.72)$.

Mean $( \pm \mathrm{SD})$ FGSI of died patients was $13.00( \pm 1.41)$.

Statistical analysis with $\mathrm{t}=$ test showed significant difference $(\mathrm{t}=2.24, \mathrm{p}=0.037)$ (Table. VIII)

The table IX shows the association between survived \& Died patients with FGSI score. Statistical analysis pearson Chi square $\left(X^{2}\right)$ test showed significant association $\left(\mathrm{x}^{2}=5.86, \mathrm{p}=0.035\right)$.

Table VII:- Comparison between delay of hospital admission and final outcome $(\mathrm{N}=22)$

\begin{tabular}{|c|c|c|c|c|c|c|}
\hline \multicolumn{2}{|c|}{ Final Outcome } & Frequency $(\mathrm{N}=22)$ & Mean & Std & t-value & p-value \\
\hline \multirow[t]{2}{*}{ Delay } & Survived & 20 & 7.50 & 4.058 & \multirow[b]{2}{*}{0.733} & \multirow[b]{2}{*}{$<0.001$} \\
\hline & Died & 2 & 9.50 & 3.53 & & \\
\hline $\begin{array}{l}\text { statistics } \\
\text { S:Signifi } \\
\text { p value i }\end{array}$ & $\begin{array}{l}\text { s calculatec } \\
\text { t } \\
\text { snificant w }\end{array}$ & $\begin{array}{l}\text { student's t test } \\
t \text { is }<0.05\end{array}$ & & & & \\
\hline
\end{tabular}

Table VIII:- Comparison of Fournier s gangrene severity index ( FGSI) With Final outcome(N=22)

\begin{tabular}{|c|c|c|c|c|c|c|}
\hline Final Outcome & Number & Mean & Std Deviation & t-value & p-value \\
\hline \multirow{2}{*}{ FGSI } & Survived & 20 & 6.95 & 3.72 & \multirow{2}{*}{2.24} & \multirow{2}{*}{$\mathbf{0 . 0 3 7}^{\mathbf{S}}$} \\
\cline { 2 - 5 } & Died & 2 & 13.00 & 1.41 & \\
\hline \\
statistics was calculated by student's t test \\
S:Significant \\
p value is significant when it is <0.05
\end{tabular}

Table XI:- Association of FGSI with Final outcome (N=22)

\begin{tabular}{|c|c|c|c|c|c|}
\hline \multirow[t]{2}{*}{ FGSI Group } & \multicolumn{2}{|c|}{ Final outcome $(\mathrm{N}=22)$} & \multirow[b]{2}{*}{ Total $(\%)$} & \multirow[b]{2}{*}{$X^{2}$} & \multirow[b]{2}{*}{ p value } \\
\hline & Survived(n=20) & $\operatorname{Died}(n=2)$ & & & \\
\hline $1-5$ & $9(100 \%)$ & $0(0 \%)$ & $9(100 \%)$ & \multirow[b]{3}{*}{5.86} & \multirow[b]{3}{*}{$0.035^{\mathrm{S}}$} \\
\hline 6-10 & $7(100 \%)$ & $0(0 \%)$ & $7(100 \%)$ & & \\
\hline$>10$ & $4(66.7 \%)$ & $2(33.3 \%)$ & $6(100 \%)$ & & \\
\hline Total & $20(90.9 \%)$ & $2(9.1 \%)$ & $22(100 \%)$ & & \\
\hline \multicolumn{6}{|c|}{$\begin{array}{l}\text { statistics was calculated by student's t test } \\
\text { S:Significant } \\
\text { p value is significant when it is }<0.05\end{array}$} \\
\hline
\end{tabular}

Discussion:-The patients with Fournier's gangrene usually have concomitant risk factors ${ }^{[3]}$. Since the initial reports, Fournier's gangrene has come to involve an older group of population and is known to be an infectious process with an identifiable source in $95 \%$ cases $^{[12]}$. 
It is not very much common from the point of view of surgical audit depicted in recognized text book. But this study do not agree with that statement.

The mean age of the patients was $43.90( \pm 14.820)$. The most of the patients were from 41-50 years age group. The average age in most published series from 40.9 to 61.7 years that agrees with the finding of our study ${ }^{[13]}$.

Sorensen et $\mathrm{al}^{[14]}$ in a population based study of 1641 cases, showed that age was a strong predictor of mortality (OR 4- 15, $\mathrm{P}<0.0001)$. However Tuncel et $\mathrm{al}^{[15]}$ and Corcocan et $\mathrm{al}^{[16]}$ did not find any significant age differences between survivors and non survivors.

Far from idiopathic, a source of infection could be identified in $86.4 \%$ cases and no cause was found in $13.6 \%$ cases. Among the identified causes, anorectal and cutaneous sources were found in $8(36.4 \%)$ cases in each. Disease of the urinary tract was found to be causative in $2(9.1 \%)$ cases

Clayton and co workers ${ }^{[17]}$ showed that the urogenital $(45 \%)$ is the commonest source of infection. The anorectal foci accounted for $33 \%$ of the cases while the cutaneous source accounted for $21 \%$ of the cases in their study ${ }^{[17]}$. So their reports did not match with our findings. The common urogenital causes include urethral strictures and indwelling catheter in multiple studies ${ }^{[1]}$. Similar findings were also found in our study.

In a Spanish study by Marco et al, ${ }^{[18]} 40 \%$ of the cases were of idiopathic origin, they acknowledged that the source of infection might have been overlooked in the process. In this series of patients with urogenital source of infection, urethral stricture disease was observed as well as indwelling catheters. Poor catheter care was the prime suspect here. The onset of the disease was abrupt in $15(68.2 \%)$ cases \& insidious in remaining 7(31.8\%) cases.

The disease occurs in affluent as well as in the poor community ${ }^{[19]}$. Most of the patients usually present with a delay of 2-7 days from the onset of the disease ${ }^{[20]} .45 .5 \%$ patients were from lower socioeconomic class. Financial condition is a common cause of delayed presentation.

Fournier's gangrene typically presents with a prodromal period of genital discomfort, associated with fever followed by constellation of clinical signs and symptoms including genital erythema, pain, swelling, crepitus suggestive of gas formation which may involve the anterior abdominal wall, groin, Thigh, buttock even axilla too. The progression of gangrene eventually leads to sloughing \& drainage of the area demarcating the viable from the dead tissues.

The result of the current study supports the above comments. All the patients presented with a mean $( \pm \mathrm{SD})$ delay of 7.68( \pm 3.98$)$ days (2-15). The comparison of final outcome (survived and died patients) to the duration of delay from onset of the disease and hospital admission showed statistically significant difference $\mathrm{P}<0.001$. The gangrenous process involved the scrotum only in $36.4 \%$ cases, scrotum plus perineum in $22.7 \%$ cases, scrotum plus anterior abdominal wall in $13.6 \%$ cases, and $4.5 \%$ in each cases scrotum plus penis, scrotum plus buttock, scrotum plus thigh, scrotum plus anterior abdominal wall respectively. The Testes were exposed in $40.9 \%$ cases.

Certain conditions like diabetes mellitus, obesity, alcohol intake, low socioeconomic status, malignancy, HIV , cirrhosis, vascular diseases etc are frequently associated with Fournier's gangrene ${ }^{[12]}$. In this study $4(18.2 \%)$ patients found diabetic and there was history of alcoholic intake in $2(9.1 \%)$ cases. One patient suffered from carcinoma rectum and $10(45.5 \%)$ patients were from poor social class. No associated risk factor was found in $5(22.7 \%)$ cases.

The multiplicity of organisms isolated from wound suggests that, none of them could be properly regarded as the cause of the disease. The organisms are commensals below the pelvic diaphragm and they are opportunistic in addition to their synergistic activity. Such infections are secondary complication of primary ischemic process ${ }^{[19]}$.

Many types of organisms in varying combination were isolated from culture of pus taken from the wound, such as $\mathrm{E}$ coli. streptococci, staphylococci, pseudomonas \& Peptostreptococci. E coli was the commonest organism isolated from wound of $15(68.2 \%)$ cases. To assess, the better physiological profile of patients in both outcome categories, the APACHE-II Severity score was modified to create Fournier's gangrene severity index(FGSI).The mean $( \pm \mathrm{SD})$ FGSI for survivors was $6.9( \pm 0.9)$ compared to $13.5( \pm 1.5)$ for nonsurvivors ${ }^{[7]}$. 
The admission clinical and laboratory parameters were recorded and the Fournier's Gangrene Severity Index (FGSI) was calculated. The mean $( \pm$ SD) FGSI was 5.5 $( \pm 3.44)$. The FGSI was compared to final outcome (survived and died patients) showed statistically significant difference. $(\mathrm{t}=2.24, \mathrm{p}=0.03)$

Early diagnosis, prompt and aggressive management is the most important aspect of treatment of Fournier's gangrene. Clinical differentiation of Necrotizing fasciitis from cellulites may be difficult because initial signs including pain, oedema, erythema are not distinctive. However, presence of marked toxicity out of proportion to the local findings should alert the clinicians about rapid hemodynamic resuscitation. Antimicrobial treatment with broad spectrum combinations followed by prompt and aggressive surgical debridement along with treatment of the predisposing causes is the recommended management of Fournier's gangrene.

The observation of the present study supports the above comments. Rapid hemodynamic resuscitation was done with I/V fluid and/or blood followed by administration of combined parental antibiotic. Prompt and aggressive surgical debridement was done. $18.2 \%$ patients were diabetes which was brought under control with Insulin therapy. None of the 22 patients gave history of immunization. Tetanus prophylaxis was done routinely. A mean $( \pm \mathrm{SD})$ of $1.63( \pm 0.90)$ number of debridement was done. The number of debridement was compared with final outcome (survived and died) which showed significant difference. $(\mathrm{t}=23.39, \mathrm{p}=.003)$. Resurfacing of the residual defect was done using secondary suturing technique, partial thickness skin grafting and local pedicle flap coverage.

Statistical analysis of FGSI with final outcome (survived and died) showed significant association. $\left(\mathrm{x}^{2}=5.86\right.$ $\mathrm{p}=0.035$ ). During treatment 6 (27.3) developed complication including septicemia, ARDS, CRF and respiratory tract infection. The mean $( \pm$ SD) hospital stay was $31.86( \pm 23.48)$ days.

The mortality rate varies from 0-67\% in different studies. The duration of stay at the hospital for Fournier's gangrene ranged between 2-278 days ${ }^{[21]}$. Contrary to the previous literature mortality rate was $9.1 \%$ ( 2 out of 22 cases). The mean $( \pm \mathrm{SD})$ duration of hospital stay was 31.86(23.48). Statistically significant association could not be established between Diabetic patients and complications that developed during treatment. $\left(\mathrm{x}^{2}=5.755, \mathrm{p}=0.218\right)$. (Data not shown)

This study also revealed that non survivors had a significantly larger body surface area involvement compared with survivors and that a body surface area of greater than 5\% was significantly associated with poor outcome $(\mathrm{p}=0.004)\left(\right.$ data not shown). This is similar to studies by Palmer et $\mathrm{al}^{[22]}$ and Spinark et al ${ }^{[23]}$ which showed that patients with a body surface area involvement of greater that 5\% have a higher mortality. They noted that survival is not directly proportional to body surface area involvement. ${ }^{[15]}$ The extent of body surface area involvement would indicate severity of disease hence its association with mortality. This issue remains debatable as some authors dispute the association of body surface area involvement with poor outcome ${ }^{[16]}$.

A number of studies have shown the effectiveness of hyperbaric oxygen therapy, as it provides adequate oxygen for optimal neutrophil phagocytic function, inhibits anaerobic growth, increases fibroblast growth and angiogenesis, reduces edema by vasoconstriction, increase intracellular transport of antibiotic\& increased generation of oxygen free radicals ${ }^{[2]}$. However, this technology was not available in our hospital and therefore could not be used.

In some centers, colostomy is routinely performed to prevent fecal contamination of the wound ${ }^{[24]}$. None of the patient needed colostomy and did well regarding wound healing. Simple washing of the wound was all that was ensured after defecation.

\section{Conclusion:-}

Fournier's gangrene is not very much frequent still yet in our context. But though we don't want to say that it is a very rare disease. All the patients presented with the disease are elderly and from predominantly lower class. The prominent clinical features are pain, fever, scrotal erythema, and sloughing of the perineo-scrotal skin with foul smelling discharge. The basis of good management remains aggressive surgical debridement, broad spectrum parental antibiotics and intensive supportive care followed by resurfacing of residual defect either by secondary suturing or by skin grafting. 


\section{References:-}

1. Corman JM, Moody JA, Aranson WL: Fournier's gangrene in a modern surgical setting: improved survival with aggressive management. Br J Urol Int 1999, 84:85-8.

2. Smith GL, Bunker CB, Dineeen MD. Fournier's gangrene. Br J Urol 1998;81:347-55.

3. Planelles Gómez J, Vergés Prósper A, Rubio Tortosa I, Beltrán Armada J R, Carrascosa Lloret Vy San Juan de Laorden C. Gangrena de Fournier". Arch. Esp. Urol. 2006; 59, (8) 767-71.

4. Descamps V, Aitken J, Lee MG. Hippocrates on necrotising fasciitis [letter]. Lancet 1994; 344:556.

5. Eke N. Fourniers gangrene: a review of 1726 cases. Br J Surg 2000;87:718-28.

6. Morpurgo E, Galandiuk S. Fournier's gangrene. Surg Clin N Am 2002;82:1213-24.

7. Laor E, Palmer TS, Tolia BM, et al. Outcome prediction in patients with Fournier's gangrene. J Urol 1995;154:89-92.

8. Patty R, Smith AD. Gangrene and Fourniers gangrene. Urol Clin North Am 1992;19:149.

9. Chawla SN, Gallop C, Mydlo JH. Fournier's gangrene: an analysis of repeated surgical debridement. Eur Urol 2003;43:572-5.

10. Singh G, Chawla S. Aggressiveness-- The key to a successful outcome in necrotiging soft tisssue infection. MJAFI 2003; 59: 21-4.

11. Unalp H.R, Kamer E, Derici H,Atahan k, Balci U,Demirdoven C, Nazli O, Onal M,A. et al. Fournier's gangrene: Evaluation of 68 patients an analysis of prognostic variables. J postgrad Med. 2008;54: 102-5.

12. Santora T, Rukstalis D B, 2007. Fournier gangrene. Jan /29 .http://www.emedicine.com/med/topic2814.htm(7of 19) $\{5 / 31 / 2016$ 11:56:26 PM $\}$.

13. López Samano V, Ixquiac-Pineda G, Maldonado Alcaraz E, Montoya G, Serrano Brambila E, Peralta Alarcon J. Gangrena de Fournier: Experiencia en Hospital de Especialidades del CMN SXXI" Arch Esp Urol, 2007: 60 (5): $525-30$.

14. Sorensen MD, Krieger JN, Rivara FP, Klien MB, Hunter W.Fournier's gangrene: population based epidemiology and outcomes. J Urol (2009);181:2120 - 6.

15. Tuncel A, Aydin O, Tekdogan U, Nalcacioglu V, Capar Y, Atan A. Fournier's gangrene: three years of experience with 20 patients and validity of the Fournier's Gangrene Severity Index Score. Eur Urol 2006;50(4):838-43.

16. Corcoran AT, Smaldone MC, Gibbons EP, Walsh TJ, Davies BJ. Validation of the Fournier's gangrene severity index in a large contemporary series. J Urol 2008;180:944-8.

17. Clayton MD, Fowler JE Jr, Sharifi R, et al. Causes, presentation and survival of fiftyseven patients with necrotizing fasciitis of the male genitalia. Surg Gynecol Obstet 1990;170:49-55.

18. Marco S L, Budia A, Di Capua C et al. Evaluation of a severity score to predict prognosis of Fournier's gangrene; BJU International, 2009;106:373-6.

19. EKE N. Fournier's gangrene: a review of 1726 cases Br J of surg 2000;87: 718-28.

20. Paty R, Smith AD. Gangrene and Fournier's gangrene. The Urol clin of North Am 1992;19: 149-62.

21. Unal B, Kocer B, Ozel E, Boskurt B,Yildirim O,Altun B, Dolapci M,Cengir O. et al. Fournier gangrene Approaches to diagnosis and treatment. Saudi Med 2006; 27:1038-43.

22. Palmer LS, Winter HI, Tolia BM, Reid RE, Laor E. The limited impact of involved surface area and surgical debridement on survival in Fournier's gangrene. British Journal of Urology 1995;76: 208-12.

23. Spinark JP, Resnick MI, Hampel N, Persky L. Fournier's gangrene: report of 20 patients. J Urology. 1984; 131:289-91.

24. Ayan F, Sunamak O,Paksoy S.M,Polat S.S, Sakoglu N, Cetnkale O, Sirin F. et al 2005. Fournier's gangrene: A Retrospective clinical study on Forty-one patients. ANZ. Surg; 75: 1055-8. 